\title{
PERCEPÇÃO FEMININA DIANTE DA GRAVIDEZ INTERROMPIDA: ANÁLISE DA EXPERIÊNCIA VIVENCIADA POR MULHERES COM DIAGNÓSTICO DE ABORTAMENTO
}

\author{
PERCEPTION OF A FEMALE BEFORE INTERRUPTED PREGNANCY: \\ ANALYSIS OF THE SITUATION EXPERIENCED BY WOMEN WITH \\ ABORTION DIAGNOSIS
}

\section{PERCEPCIÓN FEMENINA FRENTE AL EMBARAZO INTERRUMPIDO: ANÁLISIS DE LA EXPERIENCIA VIVIDA POR MUJERES CON DIAGNÓSTICO DE ABORTO}

\author{
Francisco Rosemiro Guimarães Ximenes Neto * \\ Ivo Alves De França ${ }^{* *}$ \\ Regina Célia Carvalho da Silva ${ }^{* * *}$ \\ FABIANE DO AMARAL GUBERT ${ }^{* * * *}$ \\ Izabelle Mont'Alverne Napoleão Albuquerque ${ }^{* * * * *}$
}

\begin{abstract}
RESUMO
O processo de gestar, na vida das mulheres, traz consigo mudanças físicas, comportamentais e psicológicas. No entanto, no que se refere à gravidez interrompida, esta pode ter conseqüências marcantes que influenciam na qualidade de vida dessa população. O objetivo deste estudo é descrever a percepção de mulheres atendidas em uma unidade hospitalar acerca da vivência de uma gravidez interrompida por diagnóstico de abortamento. Trata-se de um estudo descritivo, com abordagem qualitativa, em um centro obstétrico em Sobral-Ceará, Brasil. Os sujeitos do estudo são treze mulheres que procuraram assistência no período. Para coleta de dados foi utilizada entrevista semi-estruturada com intuito de conhecer o universo das participantes. Os achados evidenciam que o sentimento presente entre as participantes demonstra que a gravidez interrompida aflora atitudes distintas em cada mulher. As condições econômicas e sociodemográficas exercem influência de forma variável. Desse modo, os profissionais da saúde podem oferecer o suporte necessário para as mulheres que passam por essa experiência e que venham a engravidar futuramente, de forma saudável.
\end{abstract}

Palavras chave: Aborto, saúde da mulher, saúde sexual e reprodutiva.

\section{ABSTRACT}

The gestating process, involves physical, psychological and behavioral changes in the lives of women; however, interrupted pregnancy may have consequences affecting the quality of life in this population. The aim of this study is to analyze the perception of women attending a hospital unit, about the experience of interrupted

\footnotetext{
*Enfermeiro sanitarista. Docente do Curso de Enfermagem da Universidade Estadual do Vale do Acaraú-UVA Sobral, Ceará. Email: rosemironeto@gmail.com.

"*nfermeiro. Emergência da Santa Casa de Misericórdia de Sobral. Brasil. Email: ivoaaff@gmail.com.

${ }^{* * *}$ Enfermeira. Docente do Curso de Enfermagem da UVA. Ceará. Brasil. Email: eginacarvalho741@hotmail.com.

${ }^{* * * * *}$ Enfermeira. Doutoranda em Enfermagem pela Universidade Federal do Ceará. Bolsista CAPES, Fortaleza, Ceará - Brasil. Email: fabianegubert@hotmail.com.

${ }^{* * * * * *}$ Enfermeira. Professora do Curso de Enfermagem da UVA. Doutoranda em Enfermagem pela Universidade Federal do Ceará-UFC.
} 
pregnancy by abortion diagnosis. This is a descriptive, qualitative approach, in a birth center in Sobral, Ceará, Brazil. The subjects were thirteen women who sought assistance in a given period. For data collection, a semistructured interview with the intention of determining the universe of participants, was used. Results show the present feeling among participants and show that interrupted pregnancy brings out different attitudes in every woman. The economic and socio-demographic conditions impact of varying ways. Thus, health professionals can provide the necessary support for women going through this experience, may become pregnant in the future, in a healthy condition.

Key words: Abortion, women's health, sexual and reproductive health.

\section{RESUMEN}

El proceso de gestar conlleva cambios físicos, psicológicos y de comportamiento en la vida de las mujeres, sin embargo el embarazo interrumpido puede tener consecuencias que afecten la calidad de vida de esta población. El objetivo del estudio es analizar la percepción de las mujeres atendidas en una unidad hospitalaria, sobre la vivencia de un embarazo interrumpido por diagnóstico de aborto. Se trata de un estudio descriptivo, con abordaje cualitativo, en un centro obstétrico en Sobral-Ceará, Brasil. Los sujetos de estudio fueron trece mujeres que buscaron asistencia en un determinado periodo. Para la recolección de datos se utilizó una entrevista semiestructurada con la intención de conocer el universo de las participantes. Los resultados evidencian el sentimiento presente entre las participantes y muestran que el embarazo interrumpido hace aflorar actitudes distintas en cada mujer. Las condiciones económicas y sociodemográficas influyen de forma variada. Así, los profesionales de salud pueden ofrecer el apoyo necesario para que las mujeres que pasan por esta experiencia puedan embarazarse a futuro en condiciones saludables.

Palabras clave: Aborto, salud de la mujer, salud sexual y reproductiva.

Fecha recepción: 12/05/08 Fecha aceptación: 05/04/2011

\section{INTRODUÇÃO}

$\mathrm{Na}$ puberdade, a sexualidade evidencia-se como um processo natural o qual envolve vários aspectos: físicos, psicoemocionais e sócioculturais, relacionados à percepção e ao controle do próprio corpo, valores e comportamentos diante de processos que integram a afetividade e sexualidade, na busca do desenvolvimento sexual saudável para a vida adulta e para a futura gravidez (1).

Com o desenvolvimento da sexualidade, os sujeitos apresentam pensamentos relativos ao prazer e sensações de descobertas ao tocar o corpo; afetos brotam por determinado perfil de sujeito assim como a imagem corporal ideal. Já em relação à sexualidade, surgem necessidades relativas a um relacionamento estável; assistência à saúde reprodutiva e decisões sobre a gravidez. A gestação, para a grande maioria das mulheres, é uma fase de realização tanto pessoal quanto pelo relacionamento amoroso-conjugal e biológico, devido o instinto de procriação (2).

O processo de gestar é um processo natural e deve ser visto além de sua esfera biológica, trazendo consigo mudanças comportamentais e psicológicas, que envolvem sentimentos femininos com relação à criança, seu futuro e às relações familiares. Tais mudanças exigem adaptação no que se refere ao estado gravídico, pois a princípio ao se perceberem gerando uma vida em seu ventre, sentem-se preocupadas com a perfeita morfologia de seus filhos; mas, ao longo da gestação, esse sentimento é superado (3).

O psicodinamismo que acompanha a gravidez, atualmente, trás como conceito para as mudanças ocorridas, o termo crises evolutivas. O conceito sugere que existem períodos na vida dos sujeitos em que a emergência dos fatos, seja por ocorrência natural ou acidental, exige resposta adaptativa. Esse período 
de transição é caracterizado por distúrbios nas áreas afetiva e intelectual que implicam na utilização de novas formas, recursos e soluções que, na medida de sua realização, contribuem para o desenvolvimento da personalidade do sujeito e assim surgindo um novo período de equilíbrio (4).

Fatores como as condições sócio-econômicas, educacionais, o estado civil, relacionamento familiar, local de moradia, idade e paridade, também incidem diretamente sobre o estado emocional da grávida. No entanto, não é correto afirmar qual dessas variáveis exerçam maior influência e/ou poder decisivo sobre a psicodinâmica gestacional (5).

Diante de todos esses fatores, a interrupção da gravidez está intimamente relacionada ao abortamento, o qual pode ser espontâneo ou provocado. $\mathrm{O}$ aborto é caracterizado por um processo fisiológico do corpo com o fim da vitalidade intra-uterina e, geralmente é anunciada de maneira drástica, devido à forma ou quadro clínico; pois, mesmo que a mulher não tenha conhecimento sobre os aspectos científicos e obstétricos, a suspeita da finalização da gestação é percebida, visto que o saber popular sobre os riscos durante a gravidez é conhecido, e o próprio corpo sinaliza que algo está ocorrendo e, nesse momento, se inicia o sentimento feminino sobre o fim da gravidez (6).

Em relação aos óbitos maternos, o Ministério da Saúde Brasileiro considera o aborto, no país, um problema de saúde pública. Com base em dados da Organização Mundial de Saúde-OMS, estima-se que no Brasil, 31\% das gestações são interrompidas. O número equivale a um milhão de abortos ilegais por ano. No Sistema Único de Saúde-SUS, em 2006, foram 2,6 mil internações em decorrência do procedimento. Tal realidade evidencia o impacto que este procedimento tem sobre a saúde da mulher em nosso país (6). Em nível mundial, a OMS estima que 25\% das gravidezes culminam com um aborto provocado, representando, aproximadamente, 50 milhões de abortos anuais. Sendo que, destes, 20 milhões são praticados em condições perigosas (7).

O abortamento, no Brasil, contribui com 10 a 15\% dos óbitos maternos, representando a quarta causa de mortalidade materna e está intimamente relacionado às desigualdades sociais brasileiras (8).

Frente a essa realidade, durante vivências na Clínica Hospitalar, percebeu-se que muitas mulheres procuravam atenção obstétrica especializada, devido o aborto, por diversos motivos relatados por elas, após o tratamento, algumas clientes exteriorizavam seus sentimentos em relação à perda, necessitando de suporte psicológico, enquanto outras não expressavam qualquer tipo de sentimento, e enfrentavam o acontecido como a cura para a sua "gravidez-problema", mostrando sua opinião sobre o estado gravídico como um estado patológico. Assim, o presente estudo tem o objetivo de descrever a percepção de mulheres atendidas em uma unidade hospitalar, acerca da vivência de uma gravidez interrompida por diagnóstico de abortamento.

\section{SUJEITOS E MÉTODO}

Estudo de natureza descritiva sob abordagem qualitativa, realizado no período de abril de 2005 a janeiro de 2006, no Centro Obstétrico Rita Carmem do Hospital Dr. Estevam Ponte, Sobral - Ceará, Brasil, com 13 mulheres, com diagnóstico de abortamento e que necessitavam da realização de tratamento clínico-cirúrgico, a exemplo da curetagem uterina, procedimento utilizado para esvaziar a cavidade uterina (9).

Para a coleta de dados foi utilizada entrevista semi-estruturada contendo informações sobre o sentimento feminino diante de uma gravidez interrompida, buscando deslumbrar o universo das participantes. Minayo menciona que a entrevista semi-estruturada, pelo seu caráter flexível, na medida em que não apresenta uma padronização de pergun- 
ta e resposta (10). Os dados da entrevista semi-estruturada estão analisados a partir de categorias com as discussões de pontos relevantes, com base na literatura pertinente. A autora completa, afirmando, que trabalhar com categorias, permite agrupar elementos, sentimentos, ou expressões dos participantes (11). As categorias surgidas após a sistematização das entrevistas foram: Não planejou, mas queria ter o filho; Acho que perdi por causa de uma raiva ou susto; Foi melhor ter perdido!; Tinha desejado engravidar.

Para preservação dos sujeitos do estudo foram utilizados nomes fictícios a fim de garantir os aspectos éticos e legais da pesquisa com seres humanos, conforme o estabelecido pela Resolução No 196/1996 do Conselho Nacional de Saúde-CNS do Brasil $(12,13)$. Para as participantes adolescentes foi utilizado o termo de consentimento para os pais e buscou-se, inicialmente, a permissão da Direção do Hospital e, em seguida, o Protocolo de Pesquisa foi encaminhado ao Comitê de Ética e Pesquisa da Universidade Estadual do Vale do Acaraú-UVA.

\section{RESULTADOS}

\section{Categorias abstraídas \\ Não planejou, mas queria ter o filho}

[...] Quando soube que estava grávida eu fiquei sem saber o que estava sentindo, mas com o tempo fui aceitando [...] (Maria).

[...] Usava camisinha, mas ela furou e eu engravidei, não gostei quando soube que tava grávida, mas quando soube que era menina pelo ultrassom eu comecei a gostar que estava grávida porque só tenho três meninos [...] (Edite).

Eu usava camisinha para não engravidar, não sei o que aconteceu pra eu ter pegado menino. Fiquei muito triste por ter perdido meu filho [...] (Sara).

Não sei direito o que estou sentindo, que- ria ter tido meu filho mesmo, fico triste por isso [...] (Jane).

A gravidez, para a grande maioria das mulheres, representa a busca de sua identidade enquanto mulher. $\mathrm{O}$ fato de se tornar mãe, para as participantes do estudo, não representa somente a realização pessoal ou familiar, mas a expressão da sexualidade e poder reprodutivo, momento em que se sentem valorizadas, perante a família e sociedade, surgindo um sentimento materno de bem-querer com relação à criança que viria ao mundo (14).

Nos discursos das participantes, o risco iminente de perda da criança provoca um sentimento de decepção, frustração, e até luto pelo ente expulso da cavidade uterina, antes de poder viver sem dependência direta do corpo da mãe. Essa realidade pode ser vista comumente nos centros obstétricos, com mulheres em processo de abortamento inevitável e ao conversarem sobre o ocorrido $(15,16)$, entram em crises de choro, tanto pela morte do compito quanto por sentiremse incapazes de manter uma gravidez até o período de viabilidade da criança, achando que não estão desempenhando a função reprodutiva feminina, efetivamente.

A princípio, ao saber ou suspeitar de que está grávida, a mulher pode ficar vulnerável em relação à descoberta. Autores relatam que esses sentimentos conflituosos definem um período de adaptação, que surge junto ao estado gravídico, visando a alcançar a estabilidade emocional (17).

Nos discursos das participantes, o risco iminente de perda da criança provoca um sentimento de decepção, frustração, e até luto pelo ente expulso da cavidade uterina antes de poder viver sem dependência direta do corpo da mãe. Essa realidade pode ser vista comumente nos centros obstétricos, com mulheres em processo de abortamento inevitável e ao conversarem sobre o ocorrido (11), entram em crises de choro, tanto pela morte do compito, quanto por sentirem-se 
incapazes de manter uma gravidez até o período de viabilidade da criança, achando que não estão desempenhando a função reprodutiva feminina efetivamente.

Já o luto é um dos acontecimentos que faz parte do sentimento natural do ser humano: a morte ou perda de um ente. Uma gravidez, significa a morte de uma criança que não chegou ao período de viabilidade. Algumas mulheres podem não desenvolver o luto instantaneamente pós-aborto e sim, em alguma parte da vida ou, raramente, não sofrer emocionalmente com tal. Uma investigação mais sistemática demonstra que as reações posteriores ao aborto são mais nocivas ao estado mental e ocorrem mais tardiamente ao evento $(18,19)$.

$\mathrm{O}$ fato de terem engravidado, de forma não planejada, não que dizer que a perda da criança foi a melhor solução ou correção para essa situação, pois para as participantes, a maior frustração é que uma criança estava por vir ao mundo, não conseguiu vencer a lei da seleção natural.

\section{Acho que perdi por causa de uma raiva ou susto}

Acho que foi porque levei um susto e porque tive muita raiva com meu irmão [...] (Maria).

Acho que perdi por causa de uma raiva que me fizeram dentro de casa (Edite).

Acho que perdi a criança de um susto que tomei [...] (Rute).

Acho que perdi por causa de um susto que levei (Sara).

[...] eu tive uma raiva e um susto no mesmo dia, acho que perdi por isso (Carla).

Acho que perdi de um susto que levei [...] (Iasmim).

As entrevistadas evidenciaram, em seus depoimentos, que a gravidez interrompida foi decorrente de um susto e/ou um momento de raiva ou extremo estresse na suas vidas, no cotidiano dentro de suas residências ou en- quanto trabalhavam. Relatam que, quase que instantaneamente ao sofrerem com o susto e/ ou com raiva, iniciaram-se hemorragias genitais e cólicas na região do baixo ventre.

Muitas vezes, com o sangramento, eram expulsas partes fetais, e isso causava grande impacto nas mulheres, visto que estão cientes de que a gravidez estar finalizando-se e como o quadro descrito é assustador. Devido a hemorragia e cólicas, muitas mulheres pensam que vão evoluir a óbito, mas mesmo com essa ameaça percebida, preocupam-se com a criança que se gerava, querendo saber sobre seu prognóstico e começam a enganar seu próprio estado psicológico, com possíveis suposições explicativas para o acontecimento.

\section{[...] comecei a chorar quando vi o sangue e umas coisas coaguladas (Maria).}

Fica evidenciado que susto, raiva e estresse alteram o organismo da mulher e, eventualmente, resulta na expulsão do concepto. Prova dessa realidade é percebida nos depoimentos nos quais algumas mulheres sentiram alterações orgânicas e tiveram como conseqüência a perda da gravidez.

A interrupção da gravidez, por essas causas, não é encontrada na literatura, trata-se de um fato relacionado a aspectos antropológicos, ao lado cultural dos sujeitos ao associarem a perda da gravidez com algum evento a fim de procurar o motivo do acontecido ou justificar o fim da gravidez. Isso faz parte da explicação dos fatos. As características distintas que apresentam os comportamentos individuais de determinado grupo social fazem parte dos comportamentos e saberes da sociedade, de forma que eventos são explicados conforme conhecimentos geracionais, mantendo o etnocentrismo (20).

\section{Foi melhor ter perdido!}

Acho que foi melhor ter perdido, já tenho quatro filhos [...] (Iasmim).

Minha família não aceitaria que eu conti- 
nuasse grávida porque sou solteira e adolescente, ai eu tomei primeiro uns chás que um homem na rua me indicou e depois tomei uns comprimidos para abortar da farmácia, Cytotec (misoprostol) [...] eu achei ter sido melhor assim porque meu namorado não tem condições e eu já trabalho pra manter minha mãe [...] (Raquel).

Eu não estou sentindo nada, porque eu não queria ter ficado grávida, a camisinha estourou e pensando bem eu acho que até foi bom porque eu não teria como criar sozinha [...] (Marta).

O sentimento com relação à criança que se desenvolve, até certo momento transforma-se de algo imensamente especial e realizador para uma situação desagradável, frustrante, desesperadora, tudo porque a gravidez ocorreu de forma inesperada, agravada pela adolescência, em alguns casos.

A gravidez, para algumas adolescentes, é relatada como um momento de realização e felicidade (21), mas para a maioria, o momento reprodutivo é encarado com tristeza, medo, indecisões e desespero, pois o filho que se desenvolve no ventre, não estava nos seus planos, sendo considerado como algo que mudará para pior todas as suas oportunidades na vida (22). Duas das falas acima refletem essa realidade, as quais comentam que a interrupção da gravidez foi o melhor, pois esta não era desejada e a expulsão do concepto apresentou-se como a melhor saída.

Para os autores, a gravidez quando "não desejada, a maternidade pode ser opressiva, já que a gestação altera o aspecto físico da mulher e a convida a reorganizar vários aspectos de sua identidade, como a relação com o seu corpo, com o pai da criança e seus planos para a vida" (23). Esse comportamento reflete fatores culturais e sociais que permeiam a questão da maternidade, a qual deve ocorrer, segundo normas sociais, somente na fase adulta e com estabilidade conjugal e, portanto, envolvendo o fator religioso, por meio do casamento. Outro ponto é a grande taxa de adolescentes que abandonam a escola nessa situação, fato que repercute não só na vida destas, mas em todo o contexto familiar (24).

Em contrapartida, uma situação agravante relacionada à gravidez não planejada é o uso de fármacos uterotônicos que provocam a dilatação do colo uterino, seguida de expulsão fetal, como misoprostol. A comercialização deste remédio possui controle especial, mas há falhas (20). O método mais conhecido para indução do abortamento continua sendo o misoprostol $(25,26)$. Em pesquisa realizada em 2008, na cidade de Maceió - Alagoas, em torno de 89,1\% dos abortos foram relacionados ao uso do misoprostol (27).

Uma das mulheres do estudo referiu ter usado chá e depois o misoprostol. Tal prática, segundo autoras, é típico na trajetória das mulheres que realizam aborto na clandestinidade (28).

\section{Tinha desejado engravidar}

Fiquei triste porque eu queria ter tido a criança, deixei de usar pílula pra engravidar [...] (Iasmim).

[...] Tinha deixado de usar pílula pra justamente engravidar por que eu queria uma criança. Meu companheiro ficou alegre quando disse que achava que tava grávida. Não queria ter perdido por que era meu filho, fiquei muito triste (Rosa).

[...] Eu queria ter engravidado, deixei de usa pílula pra engravidar e já tava fazendo pré-natal. Fico decepcionada em ter perdido por que é meu segundo aborto seguido e eu quero ter uma criança. Vou tentar engravidar de novo e até quando Deus me dá a graça de segurar meu filho (Carla).

Dentre as treze mulheres que participaram do estudo, apenas três tinham engravidado de forma planejada. Isso sinaliza que as mulheres estão vulneráveis não só para a gravidez, mas para as Doenças Sexualmente 
Transmissíveis-DST. Inconsistências nos conhecimentos sobre o uso adequado e acesso aos métodos contraceptivos e prevenção da gravidez permeiam essa realidade.

Quanto a esta realidade, a gravidez não planejada/desejada aponta uma "grave responsabilidade de saúde pública”. Em países desenvolvidos, ocorreu acentuada redução da taxa de fecundidade, desde os anos 1960. No entanto, o interesse de controlar o tamanho da prole e dar um maior espaçamento entre as gestações aumentou, enquanto que, as taxas de utilização de métodos contraceptivos não acompanharam esta tendência (7).

Apesar do pequeno número de mulheres que desejaram engravidar, é importante vislumbrar que algumas se preparam para ter filhos por meio do planejamento familiar. Essa parcela é representada por aquelas que quase sempre são casadas ou com estabilidade conjugal e buscam ter filhos no momento ideal. Relatam que a gravidez deve ser vista como saudável quando fruto de uma união estável, ponto de vista de boa parte da população. $\mathrm{O}$ argumento seria que a criança cresceria melhor em um ambiente familiar, e que o apoio do pai e da mãe resolveria, com mais efetividade, os problemas surgidos.

A princípio, quando descobrem que estão grávidas, as mulheres podem desenvolver crises emocionais com finalidade evolutiva para a adaptação ao estado gravídico, relacionado à responsabilidade que descobrem ter até o nascimento, mas isso é superado (13). Nas participantes deste estudo, notase que a reação diante da perda da criança é de decepção, desespero, tristeza profunda e abalo emocional. O luto é visível, devido ao fim antecipado da gravidez com morte da criança que se formava por desejo materno e acima de tudo, o desejo feminino, resultado do planejamento familiar e realização pessoal e familiar.

Mesmo com o impacto devido à perda, contavam que iriam tentar engravidar logo que pudessem como forma de esquecer ou superar a criança perdida, recorrendo até mesmo à religião. Acrescentamos que os ritos religiosos são parte integrante no tratamento de doenças, e essa visão já é conhecida e aceita pela antropologia, como parte de um tratamento que detém uma performance atuante a substituir um estado de fragilidade para um de força e proteção renovadas, vencendo a vulnerabilidade (29).

Em pesquisa semelhante, realizada em um município do Rio Grande do Sul, a interrupção da gravidez foi percebida pelas mulheres como um momento difícil, no qual se sentiram fragilizadas, tristes e frustradas (30), o que se assemelha a estas mulheres que tiveram uma gravidez planejada.

\section{CONSIDERAÇÕES FINAIS}

Ao engravidar, muitas mulheres encontram a realização pessoal, familiar e o aguçamento de sua feminilidade por meio da maternidade. É, pois, um meio de encontrar a sua própria identidade como mulher.

O sentimento presente na fala das participantes do estudo evidencia que a gravidez interrompida aflora atitudes distintas em cada uma. As condições econômicas e sociodemográficas exercem influência, de forma variável, transformando-se de uma percepção descrita como de alegria, realização pessoal, expressão de feminilidade, para outra, com sentimento de indecisão e até raiva, realidade que pode ser observada entre as adolescentes, por exemplo. Já em relação ao sentimento de perda, todas demonstraram o luto.

As adolescentes são as que mais relatam sentimentos negativos ao engravidarem de forma não-planejada e ao perder o feto. A transição entre a adolescência e a fase adulta, acrescentando ainda o ato de gestar, pode levar a crises psicológicas, o que representa um entrave para o alcance de projetos futuros. Outra realidade é o abandono dos estudos, tendo conseqüências sociais e econômicas que prejudicam a sociedade como um todo. 
A gravidez não-planejada, segundo o estudo, muitas vezes, ocorre sem um planejamento e, em sua maioria, não era algo esperado. As participantes relataram que engravidaram em um momento difícil de suas vidas e se referem, principalmente, à falha no uso de métodos contraceptivos como a causa principal.

Mesmo não-planejada, as mulheres referiam que, a princípio, tinham sentimentos de indecisão com relação ao surgimento da gravidez, mas que ao vivenciarem este momento, mudaram de opinião e ao perceberem o risco da gravidez ser interrompida, sentiam-se tristes, imaginando como seria essa criança que não chegou a sobreviver.

Foi observado que metade das mulheres as quais tinham perdido a gravidez, não tinham filhos, informação que alerta para a necessidade de planejamento e implementação de medidas de apoio psicológico, social e de saúde por parte dos profissionais, especialmente o enfermeiro, para uma atenção integral a fim de evitar seqüelas psicológicas decorrentes da experiência abortiva e assim, contribuir para a diminuição de traumas e transtornos mentais se instalem.

Distúrbios psicológicos estes, que devem ser observados, incluindo sua incidência, principalmente, entre as adolescentes que ainda estão em desenvolvimento físico, psicológico e social. Isso requer práticas eficazes de prevenção de gravidez precoce e de forma não planejada.

Com a ampliação dos conhecimentos sobre os sentimentos femininos enfrentados de forma adaptativa, a gravidez interrompida, pode-se oferecer um cuidado adequado à realidade das mulheres, visando, principalmente, à reação de luto. Desse modo, os profissionais da saúde podem oferecer o suporte necessário para as mulheres que passam por essa experiência, que venham a engravidar ou ter atitudes com crianças sem receios, devido a experiência abortiva e assim realizarse pessoalmente.

\section{REFERÊNCIAS}

1. Associação Brasileira de EnfermagemABEn. Adolescer: compreender, atuar e acolher. Brasília: ABEn/Ministério da Saúde; 2001. 282 p.

2. Fusco CLB, Andreone S, Silva RS. Epidemiologia do aborto inseguro em uma população em situação de pobreza Favela Inajar de Souza, São Paulo. Rev Bras Epidemiol. 2008; 11(1): 78-88.

3. Ximenes Neto FRG, Marques MS, Rocha J. Problemas vividos por las adolescentes durante la gestación. Enfermería global 2008; 7(12): 1-11.

4. Kac G, Silveira EA, Oliveira LC, Araújo DM, Sousa EB. Fatores associados à ocorrência de cesárea e aborto em mulheres selecionadas em um centro de saúde no município do Rio de Janeiro, Brasil. Rev Bras Saúde Matern Infant. 2007; 7(3): 271-280.

5. Sedgh G, Henshaw S, Singh S, Ahman E, Shah IH. Induced abortion: estimated rates and trends worldwide. Lancet. 2007; 370 (9595): 1338-45.

6. Organización Panamericana de la Salud. Unidad de Género y Salud. Equidad de género y salud en las Américas a comienzos del siglo XXI. Washington: OPS; 2006.

7. Berer M. Abortos sin riesgo: un componente indispensable de las políticas y prácticas adecuadas de salud pública. Bull World Health Organ. 2000; 78(5): 580-592.

8. Alves SV. Maternal mortality in Pernambuco, Brazil: what has changed in ten years? Reprod Health Matters. 2007; 15(30): 134-44.

9. Diniz D. Aborto e a saúde pública no Brasil. Cad Saúde Pública. 2007; 23(9): 1992-1993.

10. Minayo MCS. O desafio do conhecimento: pesquisa qualitativa em saúde. 
São Paulo/Rio de Janeiro: HUCITEC/ ABRASCO; 2009.

11. Minayo MCS. Ciência, técnica e arte: o desafio da pesquisa social. En: Minayo MCS. (Org.). Pesquisa social: teoria, método e criatividade. $22^{\mathrm{a}}$ ed. Petrópolis-RJ: Vozes; 2003. p. 9-29.

12. Brasil. Ministério da Saúde. Fundação Nacional de Saúde. Diretrizes e normas regulamentadoras de pesquisas. Inf epidemiol SUS. 1996; 5 (2), (supl. 3): 1-14.

13. Brasil. Ministério da Saúde. Conselho Nacional de Saúde. Comissão Nacional de Ética em Pesquisa. Manual operacional para comitês de ética em pesquisa. Brasília: Ministério da Saúde; 2002.

14. Souza KV, Almeida MRCS, Soares VMN. Perfil da mortalidade materna por aborto no Paraná: 2003-2005. Esc Anna Nery. Rev Enferm. 2008; 12(4): 741-9.

15. Brasil. Ministério da Saúde. Parto, Aborto e Puerpério: Assistência Humanizada à Mulher. Secretaria de Políticas de Saúde. Brasília: Ministério da Saúde; 2001.

16. Brasil. Ministério da Saúde. Secretaria de Atenção à Saúde. Departamento de Ações Programáticas Estratégicas. Área Técnica de Saúde da Mulher. Pré-natal e Puerpério: atenção qualificada e humanizada - manual técnico. Brasília: Ministério da Saúde; 2005.

17. Tedesco JJA. A grávida: suas indicações e as dúvidas do obstetra. São Paulo: Atheneu; 1999.

18. Gomes EC, Menezes RA. Aborto e eutanásia: dilemas contemporâneos sobre os limites da vida. Physis (Rio de Janeiro). 2008; 18(1): 77-103.

19. Cook RBB, Tathala M. Saúde reprodutiva e direitos humanos: integrando medicina, ética e direito. Rio de Janeiro: Cepia; 2004.

20. Frederickson HL, Wilkins-Haug L. Segredos em ginecologia e obstetrícia: respostas necessárias ao dia-a-dia, em rounds, na clínica, em exames orais e escritos. 2a ed. Porto Alegre: Artes Médicas Sul;
2000.

21. Ximenes Neto FRG, Dias MAS, Rocha J, Cunha ICKO. Gravidez na adolescência: motivos e percepções de adolescentes. Rev Bras Enferm. 2007; 60(3): 279-85.

22. Souza VLC, Corrêa MSM, Souza SL, Beserra MA. $\mathrm{O}$ aborto entre adolescentes. Rev Lat Am Enfermagem. 2001; 9(2): 427.

23. Benute GRG, Nomura RMY, Pereira PP, Lucia MCS, Zugaib M. Abortamento espontâneo e provocado: ansiedade, depressão e culpa. Rev Assoc Med Bras. 2009; 55(3): 322-327.

24. Olinto MTA, Moreira-Filho DC. Fatores de risco e preditores para o aborto induzido: estudo de base populacional. Cad Saude Publica. 2006; 22(2): 365-75.

25. Ramos KS, Ferreira ALCG, Souza AI. Mulheres hospitalizadas por abortamento em uma Maternidade Escola na Cidade do Recife, Brasil. Rev Esc Enferm USP. 2010; 44(3): 605-610.

26. Opaleye ES, Coelho HLL, Schüler-Faccini L, Almeida PC, Santos ECD, Ribeiro AJV, et al. Avaliação de riscos teratogênicos em gestações expostas ao misoprostol. Rev Bras Ginecol Obstet. 2010; 32(1): 19-35.

27. Chaves JHB, Pessini L, Bezerra AFS, Rego G, Nunes R. Abortamento provocado na adolescência sob a perspectiva bioética. Rev Bras Saude Mater Infant. 2010; 10(Supl 2): 311-319.

28. Souza ZCSN, Diniz NMF, Couto TM, Gesteira SMA.Trajetória de mulheres em situação de aborto provocado no discurso sobre clandestinidade. Acta Paul Enferm. 2010; 23(6): 732-6.

29. Alves PC, Minayo MCS, orgs. Saúde e Doença: um olhar antropológico. Rio de Janeiro: Fiocruz; 1994.

30. Bazotti KDV, Stumm EMF, Kirchner RM. Ser cuidada por profissionais da saúde: percepções e sentimentos de mulheres que sofreram abortamento. Texto Contexto - Enferm. 2009; 18(1): 147-154. 